OPEN ACCESS

Edited by:

Jianfeng Dai,

Soochow University, China

Reviewed by:

Saravanan Thangamani, Upstate Medical University,

United States

Valérie Choumet,

Institut Pasteur, France

*Correspondence:

Laura D. Kramer

laura.kramer@health.ny.gov

Specialty section:

This article was submitted to

Virus and Host,

a section of the journal

Frontiers in Cellular and Infection

Microbiology

Received: 22 May 2020

Accepted: 31 August 2020

Published: 16 October 2020

Citation:

Onyango MG, Ciota AT and Kramer LD (2020) The Vector - Host Pathogen Interface: The Next Frontier in the Battle Against Mosquito-Borne

Viral Diseases?

Front. Cell. Infect. Microbiol.

10:564518

doi: 10.3389/fcimb.2020.564518

\section{The Vector - Host - Pathogen Interface: The Next Frontier in the Battle Against Mosquito-Borne Viral Diseases?}

\author{
Maria Gorreti Onyango ${ }^{1}$, Alexander T. Ciota ${ }^{1,2}$ and Laura D. Kramer ${ }^{1,2 *}$ \\ ${ }^{1}$ New York State Department of Health, Wadsworth Center, Slingerlands, NY, United States, ${ }^{2}$ School of Public Health, State \\ University of New York at Albany, Albany, NY, United States
}

An unprecedented spread of mosquito-borne viruses and increasing populations of mosquito vectors has led to an increase in the frequency of mosquito-borne virus disease outbreaks. Recent outbreaks of Zika virus (ZIKV) and yellow fever virus (YFV), among others have led to a concerted effort to understand the biology of mosquito-borne viruses and their interaction with their vector mosquito and vertebrate hosts. Recent studies have aimed to understand the vector-host-pathogen interface and how it influences infection, tropism and disease severity in the vertebrate host. The initial replication of the pathogen at the skin bite site is crucial in determining the progression of the infection in the vertebrate host. Delineating the role of the commensal microbes in the mosquito saliva as well as how they interact with the vertebrate host keratinocytes will improve our understanding of disease immunopathology and may lead to new therapeutics.

Keywords: mosquito-borne viruses, mosquito, vector-host-pathogen, saliva, microbiome

\section{INTRODUCTION}

Mosquito-borne viruses consist of a group of pathogens including dengue virus (DENV), Zika virus (ZIKV), chikungunya virus (CHIKV) and West Nile virus (WNV) which co-circulate geographically and result in significant global health challenges (Weaver and Reisen, 2010). Population growth, deforestation, urbanization, climate change and movement of people, animals and vectors have led to recent increases in the frequency and distributions of disease outbreaks associated with mosquito-borne viruses (Roiz et al., 2014; Vasilakis and Gubler, 2016). Mosquito-borne viruses affect millions of people globally. In spite of this, several of the diseases resulting from infection with these viruses have no clinically approved therapy or vaccine to prevent them and medications for symptomatic relief are the only source of comfort for infected individuals (Jackman et al., 2019; Kazmi et al., 2020). Control measures based on avoiding mosquito bites and controlling the mosquito vector are the main prevention and control measures against most mosquito-borne viruses (Petersen et al., 2016).

At the bite site, mosquito saliva elicits an immune response in the vertebrate host, enhancing dissemination of the pathogen (Mellink and Vos, 1977; Titus et al., 2006; Styer et al., 2011; Cox et al., 2012; Conway et al., 2014; Pingen et al., 2017). Specific saliva components have been studied for their modulatory effect on blood feeding 
(Kerlin and Hughes, 1992; Ribeiro, 1992; Arca et al., 1999; Arcà et al., 2007) as well as on pathogen transmission in vertebrate hosts (Conway et al., 2014, 2016; Jin et al., 2018; Uraki et al., 2019). No study has described the role of mosquito salivary microbes as potentiating factors of virus pathogenicity, yet studies suggest that factors other than salivary proteins may contribute to disease-enhancing features of pathogen transmission by vector bites (Dey et al., 2018).

\section{VECTOR PATHOGEN HOST INTERFACE AND ITS INFLUENCE ON ARBOVIRUS TRANSMISSION}

The successful transmission of a vector-borne pathogen depends on unique interactions within a triad of interactions between pathogen -host and vector (Manning and Cantaert, 2019).

Mosquito infections with pathogens prompts complex crosstalk between different metabolic and immune pathways which include the immune deficiency (lmd), the Toll and Janus kinases and signal transducers and activators of transcription (JAK-STAT). RNA interference (RNAi) modulates virus replication (Hegde et al., 2015; Bartholomay and Michel, 2018). Autophagy, apoptosis and oxidative stress can trigger and alter the immune pathways of the arthropod (Champion and $\mathrm{Xu}$, 2017). On the other hand, the alterations of host metabolic pathways by transmitted pathogens is through the modulation of stress-inducible genes involved for instance in redox and detoxifying enzyme metabolisms (Guégan et al., 2018). The holobiont concept has demonstrated that symbiotic bacteria play an important role in host biology (Guégan et al., 2018)*.

Wolbachia, an endosymbiotic bacterium naturally found in $40 \%$ of insects has been studied extensively for its anti-viral activity. Indeed, Wolbachia has been shown to confer an antiviral effect by modifying the host intracellular environment. A competitive utilization of amino acids between the host and Wolbachia has been demonstrated (Caragata et al., 2014). This results in an altered host environment less optimal for incoming virus but favoring Wolbachia's reproduction and transmission (Lindsey et al., 2018).

Further, presence of Wolbachia induces cellular stress by increased expression of the host antioxidant proteins superoxide dismutase, peroxiredoxin and glutathione peroxidase, as well as the Wolbachia proteins superoxide dismutase and bacterioferritin (Brennan et al., 2008). The enrichment of reactive oxygen species (ROS) could potentially lead to disruption of biological macromolecules such as proteins, nucleic acids and lipids at physiological levels and activation of signaling pathways such as the extracellular signal-regulated kinase (ERK) pathway known to be critically important in mediating protection against RNA viruses such as Sindbis virus (SINV) (Müller et al., 1997; Milligan et al., 1998; Victor and Barry, 2000; Xu et al., 2013).

In spite of the immune reaction mounted, arboviruses are generally known to establish a lifelong infection in vectors (Althouse and Hanley, 2015). Arthropod-mediated transmission of arbovirus is preceded by a blood meal uptake by a mosquito resulting in the mosquito injecting the virus into the human skin (Briant et al., 2014).

Mosquito are known to possess salivary factors directly modulating host immune defenses that peak after completion of engorgement (Schneider and Higgs, 2008)*. This is important because the modification of the local environment at the feeding site which is the point of introduction of a pathogen by the mosquito where resident and migratory cells encounter the pathogen (Pingen et al., 2016; Arcà et al., 2017).

Skin cells such as epidermal keratinocytes (Surasombatpattana et al., 2011), dendritic cells (Lozach et al., 2005) or neurons (Salazar et al., 2013) are the initial targets of arboviruses upon introduction at the skin bite site. The virus attaches to the cell surface and by receptor-mediated endocytosis, gains entry into the cell, resulting in the release of the nucleocapsid and the viral RNA into the cytoplasm (Rey et al., 1995). The replication of the virus happens in the rough endoplasmic reticulum and golgi-derived membranes (Salonen et al., 2004; Mackenzie, 2005). Subsequently, the virus is packaged into progeny virion or alternatively utilized to translate additional proteins (Rey et al., 1995).

Sensing a viral infection, innate immune system of the vertebrate host acts as the first line of defense. The initial response involves the recognition of the pathogen-associated molecular patterns (PAMP) expressed by the virus in non-immune cells or cells of the innate immune system such as monocytes or macrophages, dendritic cells and natural killer cells by pattern recognition receptors (PRRs), such as the Toll-like receptor (TLR)-family or RIG-I like receptor (Ye et al., 2013; Hamel et al., 2016). After the detection of PAMPs, several signaling pathways are triggered resulting in direct secretion of interferons (IFNs) as well as expression of numerous Interferon-Stimulated Genes (ISGs) generating an antiviral state (Hamel et al., 2016).

In spite of these robust immune responses at the early onset of invasion, viruses have developed means of evading the host immune system response. Within hours of infection, many pathogens induce specialized cellular proteins also known as pathogen-recognition receptors (PRRs) which include Toll-like receptors 3 and 7(TLR3 and TLR7) (Wang et al., 2004, 2006; Daffis et al., 2008a,b; Tsai et al., 2009), retinoic acid-inducible gene 1 (RIG-I) and melanoma differentiation associated gene 5 (MDA5) (Fredericksen et al., 2004, 2008; Chang et al., 2006; Fredericksen and Gale, 2006; Kato et al., 2006). Through a mechanism yet unknown, virulent WNV strains evade PRRs detection, giving them an upper hand to replicate within the cells during the early stages of infection (Fredericksen and Gale, 2006).

Establishment of the systemic viral infection depends on different factors including the vertebrate host response to mosquito saliva (Styer et al., 2011; Cox et al., 2012; Conway et al., 2014; Pingen et al., 2017). Mosquito feeding enhances the disease severity in the vertebrate host (Edwards et al., 1998; Peters et al., 2008; Styer et al., 2011; Cox et al., 2012). Indeed, the bite of a mosquito results in an influx of neutrophils and the proliferation of myeloid cells that are permissive to infection by viral pathogens (Cox et al., 2012; Pham et al., 2012; Pingen et al., 2016). Furthermore, the mosquito bite site contains extensive edema that allows virus inoculum retention 
TABLE 1 | Mosquito saliva proteins associated with modulation of arbovirus transmission.

\begin{tabular}{|c|c|c|c|c|}
\hline Saliva protein & Source & Virus & Model of study & References \\
\hline AgBR1 & Ae. aegypti & ZIKV & Ifnar-l- Ifn $\curlyvee r^{-/-}$mice (AG129-SV129 background) & Uraki et al., 2019* \\
\hline D7 & Cx. tarsalis & WNV & C57/BL6 strain mice & Reagan et al., 2012* \\
\hline Serine protease CLIPA 3 & Ae. aegypti & DENV & IFNAR $^{-/-}$mice & Conway et al., 2014* \\
\hline AaSG34 & Ae. aegypti & DENV-2 & Stat $1^{-/-}$mice & Sri-in et al., 2019* \\
\hline LTRIN & Ae. aegypti & ZIKV & Ifn $\alpha r^{-/-}$and $L t b r^{-/-}$mice & Jin et al., 2018* \\
\hline Adenosine deaminase & Ae. aegypti & DENV & Human keratinocytes & Surasombatpattana et al., 2014* \\
\hline Aegyptin & Ae. aegypti & DENV & IRF-3/7-/--/- mice & McCracken et al., 2014* \\
\hline AaVA-1 & Ae. aegypti & DENV; ZIKV & AG6 mice (ifnar $1^{-/-}$ifngr $1^{-/-}$) & Sun et al., 2020* \\
\hline NeSt1 & Ae. aegypti & ZIKV & Ifn $\alpha r 1^{-/-}$Ifn $\gamma r^{-/-}$mice (AG129-SV129 background) & Hastings et al., 2019* \\
\hline
\end{tabular}

${ }^{\star}$ References of significant relevance.

at the bite site facilitating the infection of the cutaneous cells (Pingen et al., 2016).

\section{MECHANISMS OF MOSQUITO SALIVA ENHANCEMENT OF ARBOVIRUS INFECTION}

The underlying molecular mechanisms by which the mosquito saliva modulates the vertebrate immune system are still not fully understood, but it is known that salivary factors can modulate the functions of human cells and thus enhance or suppress viral replication and interfere with the establishment and systematic replication of the virus (Wichit et al., 2016) (Table 1).

A $15 \mathrm{kDa}$ protein, LTRIN identified in Ae. aegypti salivary glands, enhanced the transmission of ZIKV in Ifn $\alpha \gamma^{-/-}$mice (but not wild type mice) by binding to lymphotoxin- $\beta$ receptor (LT $\beta R$ ) thus inhibiting signaling via the transcription factor NF${ }_{\mathrm{K}} \mathrm{B}$ and subsequent production of inflammatory cytokines (Jin et al., 2018). Lymphotoxin is a member of the tumor necrosis factor (TNF) family of cytokines responsible for the regulation of the growth and function of lymphocytes. The LT $\beta$ R signaling pathway facilitates crosstalk between epithelial cells (the first line of defense against mucosal pathogens) and the immune cells and LTRR-deficient mice have been shown to be more susceptible to various pathogenic infections (Ware, 2005; Wang et al., 2010).

Indeed, a $34 \mathrm{kDa} A e$ aegypti saliva protein completely inhibited type I IFN expression by significantly suppressing the expression of both IFN - regulatory factors (IRF 3 and 7). The protein exerted a dose-dependent effect against the expression of AMP, hence enhancing the replication of DENV in the human keratinocytes by blocking the IRF signaling pathway (Surasombatpattana et al., 2014)*. Furthermore, Ae. aegypti D7 saliva protein was demonstrated to inhibit DENV infection in murine models by a direct interaction with DENV envelope protein (Conway et al., 2016).

Mosquito saliva enhanced CHIKV pathogenesis in a murine study by significantly downregulating inflammatory genes like TLR-3, IL-2, IFN- $\gamma$, TNF- $\alpha$ and IFN- $\beta$, while enhancing antiinflammatory genes like IL-4 and IL-10 as well as induced cellular infiltration of transmigrated inflammatory cells in dermal parenchyma (Agarwal et al., 2016). Further, it was observed that
CHIKV-infected human fibroblasts in the presence of Ae. aegypti saliva demonstrated marked decrease of type I IFN-responsive genes as well as a downregulation of phosphorylated form of STAT2, hence showing that mosquito saliva affects the host immune response via the JAK-STAT signaling pathway leading to diminished immune response and enhanced CHIKV replication (Wichit et al., 2016).

Infection of cultured macrophages, bone marrow derived dendritic cells as well as mice with WNV in the presence of Ae. aegypti saliva resulted in an increase in WNV infection by a reduction in IFN- $\beta$ levels in microphages and inducible nitric oxide synthase (iNOS) while increasing levels of IL-10. On the other hand, WNV infection was enhanced in vivo by a significant reduction of T cells recruitment as well as elevated levels of IL-10 in mice skin and lymph nodes (Schneider et al., 2010).

Apart from the mosquito saliva proteins that enhance viral infection at the bite site, exogenous microRNAs (miRNAs) have been identified in mosquito saliva (Maharaj et al., 2015)*. miRNAs are short, 18-24 nucleotide, non-coding RNAs which regulate gene expressions post-transcriptionally by binding complementarily regions, mainly in the 3' UTRs of targeted messenger RNAs. Next -generation sequencing identified several novel Ae aegypti and Ae. albopictus miRNAs specific to CHIKVinfected mosquitoes and significant inhibition of CHIKV in AAG-2 and BHK-21 cells by miR-184 indicated the importance of this miRNA in alphavirus infection and replication in host cells (Maharaj et al., 2015). Further characterization of the mechanistic basis for these interactions could result in novel therapeutic tools for arboviral control.

In addition, extracellular vesicles such as exosomes have recently emerged as a trojan horse transporting viral particles and genomes to new susceptible hosts (Altan-Bonnet, 2016). Exosomes can carry cellular proteins, lipids, nucleic acids, cytokines, chemokines, translation regulatory factors, toxins and miRNAs between cells (Tkach and Théry, 2016). Indeed, DENV infected Ae. albopictus and Ae. aegypti cells were shown to secrete extracellular vesicles that contained infectious viral RNA and proteins that were infectious to naïve mosquito and mammalian cells, including human-skin keratinocytes and blood endothelial cells. Further, mosquito extracellular vessicles from ZIKV-infected C6/36 cells infected and activated naïve mosquito and mammalian cells. In addition, C6/36 extracellular vessicles 
promoted the differentiation of naïve monocytes while inducing a pro-inflammatory state with tumor necrosis factor-alpha (TNF- $\alpha$ ) mRNA expression. Lastly, ZIKV C6/36 extracellular vessicles resulted in endothelial vascular damage and increased endothelial permeability (Martínez-Rojas et al., 2020)*. Both studies suggest that mosquito exosomes may potentially be excreted in mosquito saliva during blood feeding which may fuse with keratinocytes and endothelial cells and enhance viral transmission from vector to the vertebrate host (Sultana and Neelakanta, 2019).

\section{MICROBIOME AT THE VECTOR-HOST INTERFACE AND ITS INFLUENCE ON DISEASE OUTCOME}

Despite the knowledge of the immune modulatory role of a number of salivary proteins at the vector- pathogen- vertebrate interface (Reagan et al., 2012; Conway et al., 2014; McCracken et al., 2014; Surasombatpattana et al., 2014; Jin et al., 2018; Hastings et al., 2019; Sri-in et al., 2019; Uraki et al., 2019; Sun et al., 2020), a gap exists in knowledge of the impact of the interactions between salivary associated bacterial flora and the vertebrate host (Sharma et al., 2014; Finney et al., 2015).

Asaia, a bacterium that dominates mosquito-associated microbiota, has been identified in the saliva of Anopheles stephensi and A. gambiae (Favia et al., 2007; Damiani et al., 2010). Fluorescent-labeled Asaia successfully colonized 32\% of salivary glands of colony-reared Anopheles stephensi mosquitoes demonstrating that gut microbiota can efficiently cross tissue barriers and colonize peripheral organs (Favia et al., 2007)*.

Further, (Sharma et al., 2014)*, applied a metagenomics approach to study the mosquito salivary gland microbial community structure of laboratory reared A. culicifacies demonstrating that mosquito salivary glands contain more complex microbial communities than the midgut, dominated by bacteria of the phylum Proteobacteria. The results showed that bacteria are equally associated with each of the three salivary lobes, very important tissues associated with pathogen transmission. The potential for interactions between co-existing arboviruses and microbes in the salivary gland and saliva of mosquitoes to influence transmissibility is completely unstudied. Upon skin penetration, the mosquitoes move their stylets back and forth to locate a blood vessel. During this probing phase, mosquitoes salivate copiously (Griffiths and Gordon, 1952*; Ribeiro, 1984). The possibility of introduction of bacterial microbes to the bite site via the mosquito saliva is plausible.

These microbes could interact with the skin epidermis and dermis at the point of introduction during blood meal intake. Understanding the role of salivary microbes on virus transmission and virus tropism in the vertebrate host could reveal novel targets for the control of mosquito-borne diseases.

\section{DISCUSSION}

Global changes resulting in increases in density and geographic expansion of mosquito populations is a public health threat likely to result in emergence or re-emergence of mosquito-borne diseases globally. Innovative, comprehensive and cohesive research efforts focusing on interactions with the vector and the human host are needed.

Great strides have been made in the understanding of the interactions between the arboviruses, the vector and the vertebrate hosts. However, there has been an under exploration of the knowledge of the functions of mosquito-associated bacteria. Indeed, the development of techniques such as metagenomics, metatranscriptomics, metaproteomics, and metabolomics creates opportunities to improve the mechanistic knowledge of the molecular interactions of the mosquito holobiome.

Genetic engineering of mosquitoes to enhance vector immune or antiviral responses or manipulation of the vector microbiome to reduce vector competence or vector populations are methods of mitigation currently being explored to reduce the incidence of arboviruses. The development of new technologies such as CRISPR is beneficial for enabling gene manipulation of mosquitoes as well as enabling gene drive that could result in modified mosquito populations with decreased capacity for pathogen transmission (Huang et al., 2019).

While strategies focusing on population reduction and competence are promising, targeting the vector-host interface could lead to the discovery of novel control and therapeutic strategies.

Previous studies demonstrate a clear role for components of mosquito saliva influencing transmission and disease, yet the relevance of saliva bacterial microbes in the vector- host interactions is still largely unknown.

The identification of metabolically active bacteria and the discovery of novel bacterial genes modulating chemical and biological processes during viral transmission could lead to development of novel transmission barrier tools. Studies that experimentally manipulate saliva microbial profiles could further evaluate the effect of co-transmission on host disease outcome. Together, such studies could offer unique insights into the role of holobiome in vector-host interactions.

\section{AUTHOR CONTRIBUTIONS}

MO: drafted the paper. AC: participated in the writing of the paper. LK: participated in the writing of the paper. All authors contributed to the article and approved the submitted version.

\section{FUNDING}

This publication was supported by the Cooperative Agreement Number U01CK000509 funded by the Centres for Disease Control and Prevention. Its contents are solely the responsibility of the authors and do not necessarily represent the official views of the Centres for Disease Control and Prevention or the Department of Health and Human Services. We would thank Dr. Jean-Bernard Duchemin, Dr. Dilip Nag, Dr. Constentin Dieme, and Dr. Alice Trimmer for their valuable feedback and input. 


\section{REFERENCES}

*Altan-Bonnet, N. (2016). Extracellular vesicles are the trojan horses of viral infection. Curr. Opin. Microbiol. 32, 77-81. doi: 10.1016/j.physbeh.2017. 03.040

Agarwal, A., Joshi, G., Nagar, D. P., Sharma, A. K., Sukumaran, D., Pant, S. C., et al. (2016). Mosquito saliva induced cutaneous events augment Chikungunya virus replication and disease progression. Infect. Genet. Evol. 40, 126-135. doi: 10.1016/j.meegid.2016. 02.033

Althouse, B. M., and Hanley, K. A. (2015). The tortoise or the hare? Impacts of within-host dynamics on transmission success of arthropod-borne viruses. Philos. Trans. R. Soc. B Biol. Sci. 370:20140299. doi: 10.1098/rstb.201 4.0299

Arca, B., Lombardo, F., de Lara Capurro, M., della Torre, A., Spanos, L., Dimopoulus, G., et al. (1999). Salivary gland-specific gene expression in the malaria vector anopheles gambiae. Parassitologia 41, 483-487.

Arcà, B., Lombardo, F., Francischetti, I. M. B., Pham, V. M., Mestres-Simon, M., Andersen, J. F., et al. (2007). An insight into the sialome of the adult female mosquito aedes albopictus. Insect Biochem. Mol. Biol. 37, 107-127. doi: 10.1016/j.ibmb.2006.10.007

Arcà, B., Lombardo, F., Struchiner, C. J., and Ribeiro, J. M. C. (2017). Anopheline salivary protein genes and gene families: an evolutionary overview after the whole genome sequence of sixteen anopheles species. BMC Genomics 18, 1-27. doi: 10.1186/s12864-017-3579-8

Bartholomay, L. C., and Michel, K. (2018). Mosquito immunobiology: the intersection of vector health and vector competence. Annu. Rev. Entomol. 63, 145-167. doi: 10.1146/annurev-ento-010715-023530

Brennan, L. J., Keddie, B. A., Braig, H. R., and Harris, H. L. (2008), The endosymbiont Wolbachia pipientis induces the expression of host antioxidant proteins in an aedes albopictus cell line. PLoS ONE 3:e2083. doi: 10.1371/journal.pone.0002083

Briant, L., Desprès, P., Choumet, V., and Missé, D. (2014). Role of skin immune cells on the host susceptibility to mosquito-borne viruses. Virology 464-465, 26-32. doi: 10.1016/j.virol.2014.06.023

Caragata, E. P., Rancès, E., O'Neill, S. L., and McGraw, E. A. (2014). Competition for amino acids between wolbachia and the mosquito host, aedes aegypti. Microb. Ecol. 67, 205-218. doi: 10.1007/s00248-013-0339-4

Champion, C. J., and $\mathrm{Xu}$, J. (2017). The impact of metagenomic interplay on the mosquito redox homeostasis. Free Radic. Biol. Med. 105, 79-85. doi: 10.1016/j.freeradbiomed.2016.11.031

Chang, T. H., Liao, C. L., and Lin, Y. L. (2006). Flavivirus induces interferonbeta gene expression through a pathway involving RIG-I-dependent IRF3 and PI3K-dependent NF-KB activation. Microbes Infect. 8, 157-171. doi: 10.1016/j.micinf.2005.06.014

Conway, M. J., Colpitts, T. M., and Fikrig, E. (2014). Role of the vector in arbovirus transmission. Annu. Rev. Virol. 1, 71-88. doi: 10.1146/annurev-virology-031413-085513

Conway, M. J., Londono-renteria, B., Troupin, A., Watson, A. M., Klimstra, W. B., Fikrig, E., et al. (2016). Aedes aegypti D7 saliva protein inhibits dengue virus infection. PLoS Negl. Trop. Dis. 10:e0004941. doi: 10.1371/journal.pntd.0004941

Cox, J., Mota, J., Sukupolvi-Petty, S., Diamond, M. S., and Rico-Hesse, R. (2012). Mosquito bite delivery of dengue virus enhances immunogenicity and pathogenesis in humanized mice. J. Virol. 86, 7637-7649. doi: $10.1128 /$ jvi.00534-12

Daffis, S., Samuel, M. A., Suthar, M. S., Gale, M., and Diamond, M. S. (2008a). Tolllike receptor 3 has a protective role against west nile virus infection. J. Virol. 82, 10349-10358. doi: 10.1128/jvi.00935-08

Daffis, S., Samuel, M. A., Suthar, M. S., Keller, B. C., Gale, M., and Diamond, M. S. (2008b). Interferon regulatory factor IRF-7 induces the antiviral alpha interferon response and protects against lethal west nile virus infection. J. Virol. 82, 8465-8475. doi: 10.1128/jvi.00918-08

Damiani, C., Ricci, I., Crotti, E., Rossi, P., Rizzi, A., Scuppa, P., et al. (2010). Mosquito-bacteria symbiosis: the case of anopheles gambiae and Asaia. Microb. Ecol. 60, 644-654. doi: 10.1007/s00248-010-9704-8

Dey, R., Joshi, A. B., Oliveira, F., Pereira, L., Guimarães-Costa, A. B., Serafim, T. D., et al. (2018). Gut microbes egested during bites of infected sand flies augment severity of leishmaniasis via inflammasome-derived IL-1 $\beta$. Cell Host Microbe 23, 134-143.e6. doi: 10.1016/j.chom.2017.12.002

Edwards, J. F., Higgs, S., and Beaty, B. J. (1998). Mosquito feedinginduced enhancement of cache valley virus (bunyaviridae) infection in mice. J. Med. Entomol. 35, 261-265. doi: 10.1093/jmedent/3 5.3.261

Favia, G., Ricci, I., Damiani, C., Raddadi, N., Crotti, E., Marzorati, M., et al. (2007). Bacteria of the genus Asaia stably associate with anopheles stephensi, an Asian malarial mosquito vector. Proc. Natl. Acad. Sci. U.S.A. 104, 9047-9051. doi: 10.1073/pnas.0610451104

Finney, C. A. M., Kamhawi, S., and Wasmuth, J. D. (2015). Does the arthropod microbiota impact the establishment of vector-borne diseases in mammalian hosts? PLoS Pathog. 11:e1004646. doi: 10.1371/journal.ppat.10 04646

Fredericksen, B. L., and Gale, M. (2006). West nile virus evades activation of interferon regulatory factor 3 through RIG-I-dependent and -independent pathways without antagonizing host defense signaling. J. Virol. 80, 2913-2923. doi: 10.1128/jvi.80.6.2913-292 3.2006

Fredericksen, B. L., Keller, B. C., Fornek, J., Katze, M. G., and Gale, M. (2008). Establishment and maintenance of the innate antiviral response to west nile virus involves both RIG-I and MDA5 signaling through IPS-1. J. Virol. 82, 609-616. doi: 10.1128/jvi.01305-07

Fredericksen, B. L., Smith, M., Katze, M. G., Shi, P.-Y., and Gale, M. (2004). The host response to west nile virus infection limits viral spread through the activation of the interferon regulatory factor 3 pathway. J. Virol. 78, 7737-7747. doi: 10.1128/jvi.78.14.7737-7747.2004

Griffiths, R., and Gordon, R. (1952). An apparatus which enables the process of feeding by mosquitoes to be observed in tissues of a live rodent, together with an account of the ejection of saliva and its significance in malaria. Ann. Trop. Med. Parasitol. 46, 311-319.

Guégan, M., Zouache, K., Démichel, C., Minard, G., Tran Van, V., Potier, P., et al. (2018). The mosquito holobiont: fresh insight into mosquito-microbiota interactions. Microbiome 6:49. doi: 10.1186/s40168-018-0435-2

Hamel, R., Liégeois, F., Wichit, S., Pompon, J., Diop, F., Talignani, L., et al. (2016). Zika virus: epidemiology, clinical features and host-virus interactions. Microbes Infect. 18, 441-449. doi: 10.1016/j.micinf.2016.03.009

Hastings, A. K., Uraki, R., Gaitsch, H., Dhaliwal, K., Stanley, S., Sproch, H., et al. (2019). Aedes aegypti NeSt1 protein enhances zika virus pathogenesis by activating neutrophils. J. Virol. 93, 1-16. doi: 10.1128/jvi.00395-19

Hegde, S., Rasgon, J. L., and Hughes, G. L. (2015). The microbiome modulates arbovirus transmission in mosquitoes. Curr. Opin. Virol. 15, 97-102. doi: 10.1016/j.coviro.2015.08.011

Huang, Y. J. S., Higgs, S., and Vanlandingham, D. L. (2019). Arbovirusmosquito vector-host interactions and the impact on transmission and disease pathogenesis of arboviruses. Front. Microbiol. 10:22. doi: 10.3389/fmicb.2019.00022

Jackman, J. A., Shi, P. Y., and Cho, N. J. (2019). Targeting the achilles heel of mosquito-borne viruses for antiviral therapy. ACS Infect. Dis. 5, 4-8. doi: 10.1021/acsinfecdis.8b00286

Jin, L., Guo, X., Shen, C., Hao, X., Sun, P., Li, P., et al. (2018). Salivary factor LTRIN from Aedes aegypti facilitates the transmission of Zika virus by interfering with the lymphotoxin- $\beta$ receptor. Nat. Immunol. 19, 342-353. doi: 10.1038/s41590-018-0063-9

Kato, H., Takeuchi, O., Sato, S., Yoneyama, M., Yamamoto, M., Matsui, K., et al. (2006). Differential roles of MDA5 and RIG-I helicases in the recognition of RNA viruses. Nature 441, 101-105. doi: 10.1038/nature04734

Kazmi, S. S., Ali, W., Bibi, N., and Nouroz, F. (2020). A review on zika virus outbreak, epidemiology, transmission and infection dynamics. J. Biol. Res. 27, 1-11. doi: 10.1186/s40709-020-00115-4

Kerlin, R., and Hughes, S. (1992). Enzymes in saliva from four parasitic arthropods. Med. Vet. Entomol. 6, 121-126.

Lindsey, A. R. I., Bhattacharya, T., Newton, I. L. G., and Hardy, R. W. (2018). Conflict in the intracellular lives of endosymbionts and viruses: a mechanistic look at wolbachia-mediated pathogen-blocking. Viruses 10, 1-29. doi: $10.3390 / \mathrm{v} 10040141$

Lozach, P. Y., Burleigh, L., Staropoli, I., Navarro-Sanchez, E., Harriague, J., Virelizier, J. L., et al. (2005). Dendritic cell-specific intercellular adhesion 
molecule 3-grabbing non-integrin (DC-SIGN)-mediated enhancement of dengue virus infection is independent of DC-SIGN internalization signals. J. Biol. Chem. 220, 23698-23708. doi: 10.1074/jbc.M504337200

Mackenzie, J. (2005). Wrapping things up about virus RNA replication. Traffic 6, 967-977. doi: 10.1111/j.1600-0854.2005.00339.x

Maharaj, P. D., Widen, S. G., Huang, J., Wood, T. G., and Thangamani, S. (2015). Discovery of mosquito saliva MicroRNAs during CHIKV infection. PLoS Negl. Trop. Dis. 9, 18-24. doi: 10.1371/journal.pntd.0003386

Manning, J. E., and Cantaert, T. (2019). Time to micromanage the pathogenhost-vector interface: considerations for vaccine development. Vaccines 7, 1-20. doi: 10.3390/vaccines7010010

Martínez-Rojas, P. P., Quiroz-García, E., Monroy-Martínez, V., AgredanoMoreno, L. T., Jiménez-García, L. F., and Ruiz-Ordaz, B. H. (2020). Participation of extracellular vesicles from zika-virus-infected mosquito cells in the modification of naïve cells' behavior by mediating cell-to-cell transmission of viral elements. Cells 9:123. doi: 10.3390/cells9010123

McCracken, M. K., Christofferson, R. C., Grasperge, B. J., Calvo, E., Chisenhall, D. M., and Mores, C. N. (2014). Aedes aegypti salivary protein "aegyptin" coinoculation modulates dengue virus infection in the vertebrate host. Virology 468-470, 133-139. doi: 10.1016/j.virol.2014.07.019

Mellink, J. J., and Vos, B. J. (1977). Primary lymph nodes response to mosquito bites. Zeitschrift fur Parasitenkd. Parasitol. Res. 51, 187-188.

Milligan, S. A., Owens, M. W., and Grisham, M. B. (1998). Differential regulation of extracellular signal-regulated kinase and nuclear factor-кB signal transduction pathways by hydrogen peroxide and tumor necrosis factor. Arch. Biochem. Biophys. 352, 255-262. doi: 10.1006/abbi.1998. 0603

Müller, J. M., Cahill, M. A., Rupec, R. A., Baeuerle, P. A., and Nordheim, A. (1997). Antioxidants as well as oxidants activate c-fos via Ras-dependent activation of extracellular-signal-regulated kinase 2 and Elk-1. Eur. J. Biochem. 244, 45-52. doi: $10.1111 /$ j.1432-1033.1997.00045.x

Peters, N., Egen, J., Secundino, N. F. C., Debrabant, A., Kimblin, N., Kamhawi, S., et al. (2008). In vivo imaging reveals an essential role for neutorphils in leishmaniasis transmitted by sand flies. Science 321, 970-975. doi: 10.1126/science.1159194

Petersen, L. R., Jamieson, D. J., Powers, A. M., and Honein, M. A. (2016). Zika virus. N. Engl. J. Med. 374, 1552-1563. doi: 10.1056/NEJMra1602113

Pham, A. M., Langlois, R. A., and tenOever, B. R. (2012). Replication in cells of hematopoietic origin is necessary for dengue virus dissemination. PLoS Pathog. 8:e1002465. doi: 10.1371/journal.ppat.1002465

Pingen, M., Bryden, S. R., Pondeville, E., Fazakerley, J. K., Graham, G. J., and Mckimmie, C. S. (2016). Host inflammatory response to mosquito bites enhances the severity of arbovirus infection. Immunity 44, 1455-1469. doi: 10.1016/j.immuni.2016.06.002

Pingen, M., Schmid, M. A., Harris, E., and McKimmie, C. S. (2017). Mosquito biting modulates skin response to virus infection. Trends Parasitol. 33, 645-657. doi: 10.1016/j.pt.2017.04.003

Reagan, K. L., Machain-Williams, C., Wang, T., and Blair, C. D. (2012). Immunization of mice with recombinant mosquito salivary protein D7 enhances mortality from subsequent west nile virus infection via mosquito bite. PLoS Negl. Trop. Dis. 6:e1935. doi: 10.1371/journal.pntd.0001935

Rey, F. A., Franz, X., Heinz, M. C., Kunz, C., and Harrison, S. C. (1995). The envelope glycoprotein from tick-borne encephalitis virus at $2 \AA$ resolution. Nature 375, 291-298.

Ribeiro, J. (1984). Role of mosquito saliva in blood vessel location. J. Exp. Biol. $108,1-7$.

Ribeiro, J. (1992). Characterization of a vasodilator from the salivary glands of the yellow fever mosquito aedes aegypti. J. Exp. Biol 165, 61-71.

Roiz, D., Ruiz, S., Soriguer, R., and Figuerola, J. (2014). Climatic effects on mosquito abundance in mediterranean wetlands. Parasites Vectors 7, 1-13. doi: 10.1186/1756-3305-7-333

Salazar, M. I., Pérez-García, M., Terreros-Tinoco, M., Castro-Mussot, M. E., Diegopérez-Ramírez, J., Ramírez-Reyes, A. G., et al. (2013). Dengue virus type 2: protein binding and active replication in human central nervous system cells. Sci. World J. 2013, 1-10. doi: 10.1155/2013/904067

Salonen, A., Ahola, T., and Kääriäinen, L. (2004). Viral RNA replication in association with cellular membranes. Curr. Top. Microbiol. Immunol. 285, 139-173. doi: 10.1007/3-540-26764-6_5
Schneider, B., Soong, L., Coffey, L. L., Stevenson, H. L., McGee, C. E., and Higgs, S. (2010). Aedes aegypti saliva alters leukocyte recruitment and cytokine signaling by antigen-presenting cells during West Nile virus infection. PLoS One. 5. doi: 10.1371/journal.pone.00 11704

Schneider, B. S., and Higgs, S. (2008). The enhancement of arbovirus transmission and disease by mosquito saliva is associated with modulation of the host immune response. Trans. R. Soc. Trop. Med. Hyg. 102, 400-408. doi: 10.1016/j.trstmh.2008.01.024

Sharma, P., Sharma, S., Maurya, R. K., De, T., Das, T. T., Lata, S., et al. (2014). Salivary glands harbor more diverse microbial communities than gut in anopheles culicifacies. Parasit. Vectors 7:235. doi: 10.1186/1756-3305-7-235

Sri-in, C., Weng, S. C., Chen, W. Y., Wu-Hsieh, B. A., Tu, W. C., and Shiao, S. H. (2019). A salivary protein of aedes aegypti promotes dengue-2 virus replication and transmission. Insect Biochem. Mol. Biol. 111, 103-181. doi: 10.1016/j.ibmb.2019.103181

Styer, L. M., Lim, P., Louie, K. L., Albright, R. G., Kramer, L. D., and Bernard, K. A. (2011). Mosquito saliva causes enhancement of west nile virus infection in mice. J. Virol. 85, 1517-1527. doi: 10.1128/JVI.01112-10

Sultana, H., and Neelakanta, G. (2019). Arthropod exosomes as bubbles with message(s) to transmit vector-borne diseases. Curr. Opin. Insect Sci. 40, 1-9. doi: 10.1016/j.cois.2020.05.017

Sun, P., Nie, K., Zhu, Y., Liu, Y., Wu, P., Liu, Z., et al. (2020). A mosquito salivary protein promotes flavivirus transmission by activation of autophagy. Nat. Commun. 11:260. doi: 10.1038/s41467-019-1 $4115-\mathrm{z}$

Surasombatpattana, P., Ekchariyawat, P., Hamel, R., Patramool, S., Thongrungkiat, S., Denizot, M., et al. (2014). Aedes aegypti saliva contains a prominent $34-\mathrm{kDa}$ protein that strongly enhances dengue virus replication in human keratinocytes. J. Invest. Dermatol. 134, 281-284. doi: 10.1038/jid. 2013.251

Surasombatpattana, P., Hamel, R., Patramool, S., Luplertlop, N., Thomas, F., Desprès, P., et al. (2011). Dengue virus replication in infected human keratinocytes leads to activation of antiviral innate immune responses. Infect. Genet. Evol. 11, 1664-1673. doi: 10.1016/j.meegid.2011. 06.009

Titus, R. G., Bishop, J. V., and Mejia, J. S. (2006). The immunomodulatory factors of arthropod saliva and the potential for these factors to serve as vaccine targets to prevent pathogen transmission. Parasite Immunol. 28, 131-141. doi: 10.1111/j.1365-3024.2006.00807.x

Tkach, M., and Théry, C. (2016). Communication by extracellular vesicles: where we are and where we need to go. Cell 164, 1226-1232. doi: 10.1016/j.cell.2016.01.043

Tsai, Y. T., Chang, S. Y., Lee, C. N., and Kao, C. L. (2009). Human TLR3 recognizes dengue virus and modulates viral replication in vitro. Cell. Microbiol. 11, 604-615. doi: 10.1111/j.1462-5822.2008.01277.x

Uraki, R., Hastings, A. K., Marin-lopez, A., Sumida, T., Takahashi, T., Grover, J. R., et al. (2019). Aedes aegypti AgBR1 antibodies modulate early Zika virus infection of mice. Nat. Microbiol. 4, 948-955. doi: 10.1038/s41564-0190385-x

Vasilakis, N., and Gubler, D. J. (2016). Arboviruses: Molecular Biology, Evolution and Control. eds. N. Vasilakis and D. J. Gubler Poole, (Caister Academic Press).

Victor, J. T., and Barry, L. F. (2000). Reactive oxygen species in cell walls. Am. J. Lung. Cell. Mol. Physiol. 279, 215-249. doi: 10.1002/9780470988565.ch9

Wang, J. P., Liu, P., Latz, E., Golenbock, D. T., Finberg, R. W., and Libraty, D. H. (2006). Flavivirus activation of plasmacytoid dendritic cells delineates key elements of TLR7 signaling beyond endosomal recognition. J. Immunol. 177, 7114-7121. doi: 10.4049/jimmunol.177.10.7114

Wang, T., Town, T., Alexopoulou, L., Anderson, J. F., Fikrig, E., and Flavell, R. A. (2004). Toll-like receptor 3 mediates west nile virus entry into the brain causing lethal encephalitis. Nat. Med. 10, 1366-1373. doi: 10.1038/nm1140

Wang, Y., Koroleva, E. P., Kruglov, A. A., Kuprash, D. V., Sergei, A., Fu, Y., et al. (2010). Lymphotoxin beta receptor signaling in intestinal epithelial cells orchestrates innate immune responses against mucosal bacterial infection. Immunity 32, 403-413. doi: 10.1016/j.immuni.2010.02.011.Lymphotoxin

Ware, C. F. (2005). Network communications: lymphotoxins, LIGHT, and TNF. Annu. Rev. Immunol. 23, 787-819. doi: 10.1146/annurev.immunol.23.021704.115719 
Weaver, S. C., and Reisen, W. K. (2010). Present and future arboviral threats. Antiviral Res. 85, 328-345. doi: 10.1016/j.antiviral.2009.10.008

Wichit, S., Ferraris, P., Choumet, V., and Missé, D. (2016). The effects of mosquito saliva on dengue virus infectivity in humans. Curr. Opin. Virol. 21, 139-145. doi: 10.1016/j.coviro.2016.10.001

Xu, J., Hopkins, K., Sabin, L., Yasunaga, A., Subramanian, H., Lamborn, I., et al. (2013). ERK signaling couples nutrient status to antiviral defense in the insect gut. Proc. Natl. Acad. Sci. U.S.A. 110, 15025-15030. doi: 10.1073/pnas.1303193110

Ye, J., Zhu, B., Fu, Z. F., Chen, H., and Cao, S. (2013). Immune evasion strategies of flaviviruses. Vaccine 31, 461-471. doi: 10.1016/j.vaccine.2012.11.015
Conflict of Interest: The authors declare that the research was conducted in the absence of any commercial or financial relationships that could be construed as a potential conflict of interest.

Copyright (๑) 2020 Onyango, Ciota and Kramer. This is an open-access article distributed under the terms of the Creative Commons Attribution License (CC BY). The use, distribution or reproduction in other forums is permitted, provided the original author(s) and the copyright owner(s) are credited and that the original publication in this journal is cited, in accordance with accepted academic practice. No use, distribution or reproduction is permitted which does not comply with these terms. 